A Comparative study of some Immunological and Molecular Techniques to Detect Cytomegalovirus in patients

\title{
A Comparative study of some Immunological and Molecular Techniques to Detect Cytomegalovirus in patients with Kidney Failure in Diyala Governort Shahad Shaker Mahmood (MBChB) ${ }^{1}$, Abbas Abod Farhan $(\mathrm{PhD})^{2}$ and Mohmmed Abdul Daim Saleh( $(\mathrm{PhD})^{3}$
}

\begin{abstract}
Background: Kidney failure can be defined as the total failure of toxins and waste from filtration the blood. This disease is characterized by reduced glomerular filtration rate (GFR) to about $20-50 \%$, resulting in the failure to regulate the amount of fluid in the body and it is divided into two types acute and chronic renal failure .The immunity of patients with haemodialysis becomes weak and this cause viral infections such as Cytomegalovirus human cells.

Objective: To determine the relationship between kidney failure and Cytomegalovirus human cells and compare the molecular and immunological techniques in diagnose this virus. Patients and Methods: Seventy blood sample were collected from patients with kidney failure after diagnosis by specialists in the Ibn Sina Centre for dialysis and 20 individuals as acontrol. The IgG and IgM were detected by ELISA, in addition the diagnose of virus by cassette and compare the results of CMV diagnosis(by ELISA technique) with molecular technique (PCR) results.

Results: ELISA results showed that the incidence of CMV IgG was 25 patients (35.7\%) while IgM was in 5 patient $(7.1 \%)$. The incidence of $\mathrm{IgG}$ in males was $(56 \%)$. In females was $(44 \%)$. while the result of IgM in male was (100\%) and In females (5) The results of cassette showed CMV virus was seropositivity $(21.4 \%)$ for males and females with very high difference observed between the two groups of study and more differences were observed between test results and sex between test results and age groups, and showed a positive PCR test results of interaction (66.6\%) and (20) of (30) sample tested after ELISA techniques to detect IgG and IgM in comparison among three techniques used by PCR technique the best technique were IgG and IgM ELISA test results and test cassette and technique PCR molecular are $21.4 \%$ and $7.1 \%$ and $35.7 \%$ and $66.6 \%$.
\end{abstract}

Conclusion: The results showed that Cytomegalovirus has relationship with chronic and acute renal failure and can affect the patient's immune status. our results can provide an advanced diagnosis of viral infections among patients in hospitals in Iraq.

Key words: Kidney failure, Human Cytomegalovirus virus, ELISA, Polymerase chain reaction technique.

Corresponding Author: shahadbiologist@gmail.com

Received: $15^{\text {th }}$ October 2017

Accepted: $14^{\text {th }}$ November 2017

https://doi.org/10.26505/DJM

${ }^{1,2}$ Biology Department- College of Education for Pure Sciences- University of Diyala- Diyala- Iraq.

${ }^{3}$ Biotechnology Department -college of science -Univerity of Diyala- Diyala-Iraq. 


\section{Introduction}

Cytomegalovirus (CMV) is one of the viruses belonging to the herpes family. The virus contains a network of DNA, surrounded by capsid, and a phospholipid-rich membrane. Although most of the viruses in this virus are without symptoms, Patients are at risk of being infected with this virus over a long period of time as this virus affects any living cell in the body [1]. This virus can be transmitted from one person to another in many different ways, all of which require direct and close contact with the viruscarrying materials. There is a period of incubation of the virus ranging from 4-8 weeks in children and adults after exposure to the virus. This virus causes a systemic infection, Isolation of this type of virus from lung, liver, esophagus, colon, kidneys, T cells and $\mathrm{B}$ lymphocytes, like all herpes viruses, causes importent infections [2].

Immunocompromised and transplanted Frequent hemodialysis [3] has shown that the seropositive spread of infection with this virus is highest in South America and Africa While in the developed countries [4] about $70 \%$ of adults have a latent CMV infection and can be reactivated if the individual becomes Immunosuppressed . the cytomegalovirus is the most Common after kidney transplantation [5] and depending on the situation The incidence of serum infection in adults over the course of 40 years is $60-100 \%$, possibly as a result of intrauterine or intrauterine transmission, breast-feeding, blood transfusion, sexual contact and tends to be lower in developed countries than in developing countries [6]
[7]. Renal Failure is a condition in which the kidneys fail to remove the end products of metabolism from blood, regulate fluid and electrolytes, and balance $\mathrm{pH}$ in extracellure fluids [8]. This failure can occur as a result of Kidneys Disease, Systemic Disease or Urologic Defects Kidney failure is a chronic or acute disorder. Nitrogenous Wastes is a marker or early indicator of renal failure. This is often the case before any other symptoms. Urea is one of the first nitrogenous waste to accumulate in the body, the blood. Where the level of urea becomes increasingly high with the progress of the stage of renal failure and the normal concentration of urea in the plasma is usually less than $20 \mathrm{mg} / \mathrm{dl}$ and in cases of kidney failure this level rises to the highest possible up to $800 \mathrm{mg} / \mathrm{dl}$ [9].

\section{Patients and Methods}

Preparation of the sample: This study was conducted during the period between $1 / 9 / 2016$ and $1 / 3 / 2017$, where 70 blood samples were collected from dialysis patients at Ibn Sina Center in Baquba Teaching Hospital in Diyala Governorate after diagnosis by the specialist doctor. The mean blood age was $44.13 \pm 16.67$ and for the age group (1-80) years. The blood indicators of patients were recorded in the questionnaire. 5 $\mathrm{ml}$ of intravenous blood of the patients and control group included in the study was withdrawn by sterile medical syringe and divided into two parts Placed in a tube and left for 15 minutes until the coagulation occurred and then centrifuged The rate of $3000 \mathrm{rev} / \mathrm{min}$ for 10 minutes samples and 
preserved at degree $(-20)$ until the tests either Section II placed in the pipeline container material anti-clotting, a pipeline (EDTA) and saved at temperature $(-20)$ and used in molecular diagnostics.

\section{Immunological tests}

\section{1- CMV cassette rapid test}

The sample and test components were prepared to room temperature if they were refrigerated or frozen. The sample was mixed thoroughly before the test was performed, after which the cassette was placed on a clean surface. The test strip was numbered with the patient's sample number. The sample pipette is filled with sample and the droplet is retained. One drop (about 45-30ul) of the test sample is placed in the sample hole in both the right and left parts and the air bubble must be checked. Then add one drop (50-35 ul) from the sample diluent sample directly into the sample hole in both the left and right parts of the test strip .The results were read with 15 miutes.

\section{2-The ELISA test to detect IgM immune antibody to Cytomegalovirus virus test according to the manufacturer's instructions for diagnostic kit (Hannover, Germany)}

100uL of Negative Controle (Buffer) was added in wale B1 and $\mathrm{C} 1$ with the exception of wale A1. Add $100 \mathrm{uL}$ of cut -off calibrator in D1 and E1 (blue) and add $100 \mathrm{uL}$ of positive control in F1 and G1 (red). Add 100 ul diluted sample (green) To the wale in the plate starting from wale $\mathrm{H} 1$, the color changes from green to blue. After that, mix well for 30 seconds. Cover the plate with duct tape and incubate in the incubator at 3742 degrees $\mathrm{C}$ for 30 minutes. Fill each hole with a diluted wash solution. After that, add $100 \mathrm{ul}$ of the conjucgate solution to all the holes except for a blank well. Stick and incubate again for 30 minutes and then wash the plate 5 times and then in this step we add $50 \mathrm{ul}$ of the substrate A solution to all the wales and then add substrate $B$ and each time incubate for 30 minutes and wash 5 times. The last step was added stop solution solution $50 \mathrm{ul}$ and incubated for 30 minutes and then washed 5 times and left the plate to dry after which read the results along the wavelength $360 \mathrm{~nm}$.

3-The ELISA test to detect IgG immune antibody to Cytomegalovirus virus (Hannover, Germany)

A1 wale left in the standard plate is empty as a Blank and add 100 ul of calibrator 1 (yellow) in the wale B1 and $\mathrm{C} 1$, and add of calibrator 2 (blue) to wale D1 and E1 , $100 \mathrm{ul}$ of calibrator 3 was added in wale F1 and G1 and add calibrator 4 to wale A1 and H1. 1000 ul of sample diluent Specimen was added (green color) to all the remaining wales in the plate starting from B2, then add 5 ul of serum sample) sample starting from the wale where the color changes observed B2 from green to blue, then we mix the plate on the surface For 30 seconds, and then covered with duct tape and incubated for $30 \mathrm{~min}$ at $37 \mathrm{C}^{\circ}$.

Then add the Gonjugate function (red) into every drill except A1 wale (Blank) and covered with duct tape and placed in the lap for 30 minutes and $37 \mathrm{C}^{\mathbf{o}}$ temperature and then lifting tape and washed five times as in 
the previous step, then you add 50 ul of substrate A (transparent color F) to drill and then add $50 \mathrm{ul}$ of substrate $\mathrm{B}$ to drill and then we mix the mixing plate and covered with duct tape and incubated for 10 minutes at a temperature of $37 \mathrm{C}^{\mathbf{o}}$ and then we removed the tape and add $50 \mathrm{ul}$ of aqueous solution to stop interaction stopped digging, then dried and read results along Mo LG 360 nanometers.

\section{Molecular tests}

Sample extraction: (G- spin DNA extraction kit, intron biotechnology, cat. no1745).

By pipette micro pipette 200ul of total blood was withdrawn and placed in microcenterfuge tube (1.5ul) and $20 \mathrm{ul}$ of protenase $\mathrm{K}$ and $5 \mathrm{ul}$ of RNase A solution were added to the sample and mixed well. Of buffer Buffer BL (containing chaotropic salt for extra cell dissolution) in the upper sample tube carefully by micropipette, then incubate the analyzed samples for 10 minutes to fully decompose and mix the sample 3-4 times during the incubation period 200 ul From absolute ethanol to the sample and mixed well by shaking (5-6) times. The samples were transferred from the test tubes $(1,5 \mathrm{ul})$ to the spin co tubes lumen and then placed in the centrifuge for one minute at a rate of 13000 cycles / min, the filter is neglected with the collection tube and replaced with a 2 $\mathrm{ml}$ tube.In addition, $700 \mathrm{ml}$ of buffer A containing chaotropic salt was added to the new collection column and centrifuged 13000 cycles / min. Leach the filter with the reuse of the collection tube. Next step, 700 $\mathrm{ml}$ of wash Buffer B solution was added to the assembly column and placed in the centrifuge. The filter is then diluted and replaced with a $2 \mathrm{ml}$ tube and placed again in the centrifuge for one minute to dry. The combination column is transferred to a $1.5 \mathrm{ml}$ tube and a buffer $(30-100 \mathrm{ml})$ is added directly on the membrane and incubated for one minute at room temperature and then placed in the centrifuge for 1 minute. Glycoprotien B gene was used for primer cell virus primer1 (forword 5'GTATGAAACTCTTGATCGTCT-3 ') (reverse 3 5'CCGCATGATCAGGTTAGTAAT-) primer2 (forword 5'TGTCCAAGCGGTGAAACAAG- 3') (reverse 5'CAACCGTGACCCATTTACTG- 3) Investigation of the polymerization reaction results after the amplification of the DNA in the thermo cycler by electrolysis with agaros gel. The DNA Lader (1000 pb) was adopted.

\section{Statistical Analysis}

Statistical analysis was carried out using the statistical package for social sciences((statistical package for Social Sciences) with the number 22 version in terms of the variables of descriptive formula, which was described in the number and percentage formula was compared using the test box Kay, while the variables with the numerical formula has been described using the average and standard deviation of the rate and the comparison between groups using The t-test between two groups or the ANOVA test during a comparison between two groups. The correlation coefficient test 
was used below the probability level (0.01) to find the possible relationship scale between the two variables (levesque, 2007).

\section{Results}

The current study included [90] samples divided into two groups. The first group is the group of patients with renal failure. It consists of [70] samples, [45] samples of males $(64.3 \%)$ and [25] female samples (35.7\% ).The control group consisted of [20] samples, [2] male samples $(10.0 \%)$ and [18] samples of females and $90.0 \%$. The results of the present study showed that the number of males with kidney failure is more than females with a significant difference between the sexes as well as between the two study groups where $\mathrm{P}$ (value) $<0.001$ as in Table (1). In this study, one of the common immunological techniques, cassette technique, was used. After the examination of the samples of patients with renal failure and control samples, the current results showed that the CMV test results were 15 samples of 70 samples and $21.4 \%$ The mean of the control samples was [4] of the total [20] (20.0\%). There was no statistically significant difference at the $\mathrm{P}$ value $>0.05$ as shown in table (2).

Table (3) shows the immunoglobulin antibody (IgM) of the cytomegalovirus virus between the two groups of patients with apparent renal failure. The number of positive IgM patients was $5(7.1 \%$,) while the number of positive antibodies was positive [1] (6.67\%). However, no significant differences were observed at the $\mathrm{P}$ value $<0.05$. Table(4) shows the IgG antibody resistance of human cell amplifier virus between The two study groups of patients with renal failure and apparent healthy, as the number of patients positive $\mathrm{IgG}$ antibody for this virus [25)] $35.7 \%$ of the total [70] samples of patients, while the number of healthy positive IgG antibody for this virus [3] $(15 \%)$ of the total [20] with a significant difference of statistical significance at the level of probability $\mathrm{P}$ value $<0.05$. The results of the current study were positive for the human cytomegalovirus virus among the group of patients with renal dysfunction for males and females using one of the sensitive molecular techniques, PCR. The results showed that the number of infected males was positive for the interaction (14 out of 20) $(70 \%)$, while the number of females was [6] (30\%) of the total 20 statistically noting that there were no statistically significant differences between the two groups at the level $\mathrm{P}$ value $<0.05)$. As shown in Table (5). Results of the test for the diagnosis of PCR ,the group of patients with renal impairment of both sexes for age groups. The table showed that the age group (21-40) gave positive interaction and by $15 \%$ and the number [3]. The age group (41-60) (55\%) and the number [11] and the age group (61$80)$ gave a positive rate $(25 \%)$ and the number [5] and the last age group (80>) gave a positive rate (5\%) and the number [1]. There were significant differences at a probability level of (448) between age groups and both sexes ie $\mathrm{P}>0.05$. The following results show that the age group (41-60) gave the highest rate of infection among the age 
groups (55\%), as shown in Table (6). When comparing immunological and molecular techniques to diagnose human amplifier virus in patients with renal failure, the rapid technique (Cassette technique) gave serological positive $(21.4 \%$ and $15 \%)$ of the total [70] samples of the two groups, but the ELISA technique gave positive $(25.7 \%)$ and IgM antibody (7.1\%) [5] of the total(70) samples for the two study groups. the (PCR)

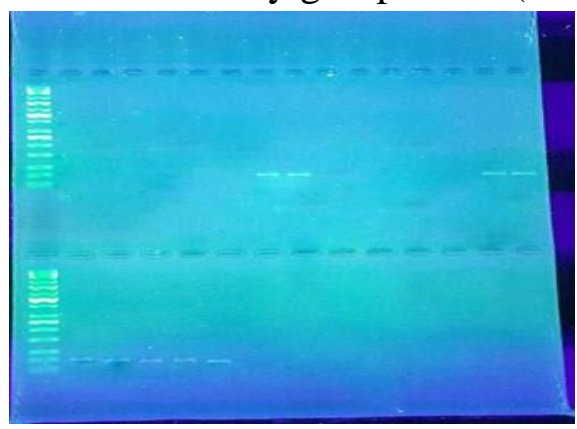

Figure (1)

The result of a PCR reaction of the Glycoprotien B gene for human cytomegalovirus for a sample of patients' samples showing $150 \mathrm{pb}$. bands on the electrophoresis machine at $2 \%$ concentration and voltages (50 volt $/ \mathrm{cm} 2)$ For an hour and a half figure (1). was positive for diagnosis by (66.6\%) Of the total (30) samples of the two study groups These results show that the current PCR technology is the best diagnostic techniques for the diagnosis of the amplifier virus For cells because they have the highest positive percentage $(66.6 \%)$ among the other techniques used in this study, as shown in Table (7).

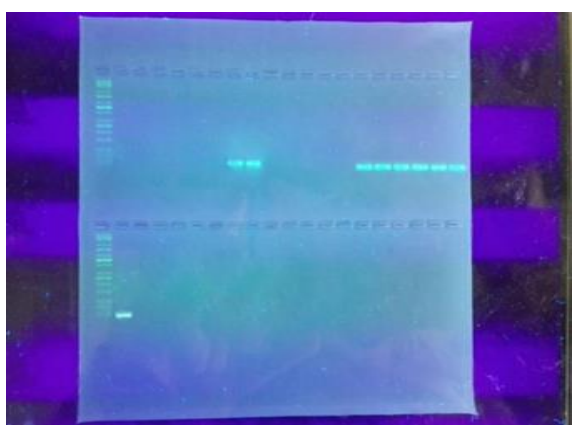

Figure (2)

The result of second primer Glycoprotien gene B diagnostic for Cytomegalovirus human cells and show (bands) size (150pb) stage on my electric relay agaros gel focus ( $2 \%$ voltage) difference $(5 \mathrm{volt} / \mathrm{cm})$ for half an hour figure (2).

Table (1): Distribution of study groups for sex.

\begin{tabular}{|c|c|c|c|c|c|}
\hline & \multicolumn{2}{|c|}{ Groups } & \multirow{2}{*}{ Total } \\
\hline & & & Patients & Control & \\
\hline \multirow{4}{*}{ Sex } & \multirow{2}{*}{ Male } & $\mathrm{N}$ & 45 & 2 & 47 \\
\hline & & $\%$ & $64.3 \%$ & $10.0 \%$ & $52.2 \%$ \\
\hline & \multirow{2}{*}{ Female } & $\mathrm{N}$ & 25 & 18 & 43 \\
\hline & & $\%$ & $35.7 \%$ & $90.0 \%$ & $47.8 \%$ \\
\hline \multirow{2}{*}{\multicolumn{2}{|c|}{ Total }} & $\mathrm{N}$ & 70 & 20 & 90 \\
\hline & & $\%$ & $100.0 \%$ & $100.0 \%$ & $100.0 \%$ \\
\hline \multicolumn{2}{|c|}{ Chi-square } & \multicolumn{4}{|c|}{18.37} \\
\hline \multicolumn{2}{|r|}{ Sig. } & \multicolumn{4}{|c|}{$0.001 * * *$} \\
\hline
\end{tabular}

*very high significant difference 
A Comparative study of some Immunological and Molecular Techniques to Detect Cytomegalovirus in patients with Kidney Failure in Diyala Governort

Shahad Shaker Mohmmed

Table (2): Cassette test results among the study group.

\begin{tabular}{|c|c|c|c|c|c|}
\hline & & & \multicolumn{2}{|c|}{ Groups } & \multirow{2}{*}{ Total } \\
\hline & & & Patients & Control & \\
\hline \multirow{4}{*}{ Cassette } & \multirow{2}{*}{ Positive } & $\mathrm{N}$ & 15 & 4 & 19 \\
\hline & & $\%$ & $21.4 \%$ & $20.0 \%$ & $21.1 \%$ \\
\hline & \multirow{2}{*}{ Negative } & $\mathrm{N}$ & 55 & 16 & 71 \\
\hline & & $\%$ & $78.6 \%$ & $80.0 \%$ & $78.9 \%$ \\
\hline \multirow{2}{*}{\multicolumn{2}{|c|}{ Total }} & $\mathrm{N}$ & 70 & 20 & 90 \\
\hline & & $\%$ & $100.0 \%$ & $100.0 \%$ & $100.0 \%$ \\
\hline \multicolumn{2}{|c|}{ Chi-square } & \multicolumn{4}{|c|}{.019} \\
\hline \multicolumn{2}{|c|}{ Sig. } & \multicolumn{4}{|c|}{$.890^{\mathrm{NS}}$} \\
\hline
\end{tabular}

*NS no significant

Table (3): Shows the results of qualitative antibodies CMV-IgM by study group.

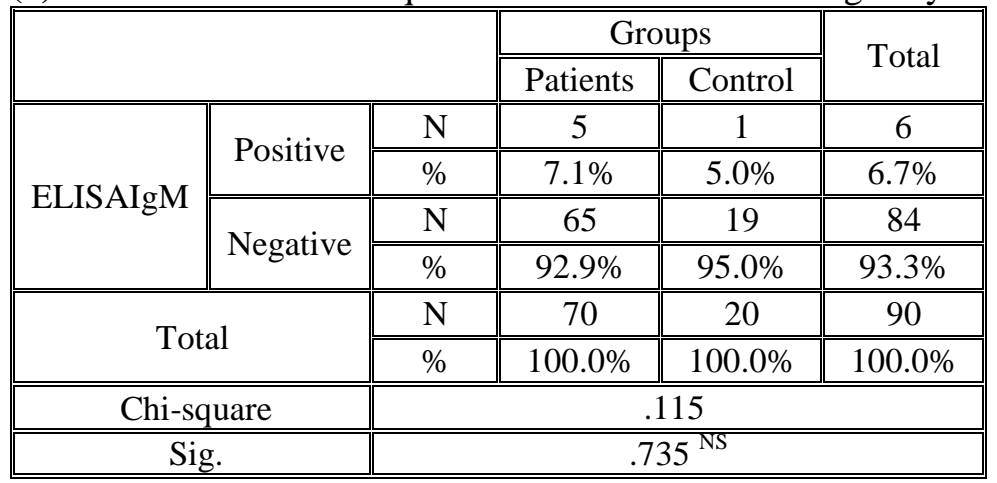

Table (4): Shows the results of qualitative antibidies CMV-IgG by study group.hows.

\begin{tabular}{|c|c|c|c|c|c|}
\hline & & & \multicolumn{2}{|c|}{ Groups } & \multirow{2}{*}{ Total } \\
\hline & & & Patients & Control & \\
\hline \multirow{4}{*}{ ELISAIgG } & \multirow{2}{*}{ Positive } & $\mathrm{N}$ & 25 & 3 & 28 \\
\hline & & $\%$ & $35.7 \%$ & $15.0 \%$ & $31.1 \%$ \\
\hline & \multirow{2}{*}{ Negative } & $\mathrm{N}$ & 45 & 17 & 62 \\
\hline & & $\%$ & $64.3 \%$ & $85.0 \%$ & $68.9 \%$ \\
\hline \multirow{2}{*}{\multicolumn{2}{|c|}{ Total }} & $\mathrm{N}$ & 70 & 20 & 90 \\
\hline & & $\%$ & $100.0 \%$ & $100.0 \%$ & $100.0 \%$ \\
\hline \multicolumn{2}{|c|}{ Chi-square } & \multicolumn{4}{|c|}{1.33} \\
\hline \multicolumn{2}{|c|}{ Sig. } & \multicolumn{4}{|c|}{$0.04 *$} \\
\hline
\end{tabular}

*significant differenc 
A Comparative study of some Immunological and Molecular Techniques to Detect Cytomegalovirus in patients with Kidney Failure in Diyala Governort

Table (5): CMV virus prevalenve to a group of patients for sex.

\begin{tabular}{|c|c|c|c|c|c|}
\hline & \multicolumn{2}{|c|}{ PCR } & \multirow{2}{*}{ Total } \\
\hline & & & Positive & Negative & \\
\hline \multirow{4}{*}{ Sex } & \multirow{2}{*}{ Male } & $\mathrm{N}$ & 14 & 7 & 21 \\
\hline & & $\%$ & $70.0 \%$ & $70.0 \%$ & $70.0 \%$ \\
\hline & \multirow{2}{*}{ Female } & $\mathrm{N}$ & 6 & 3 & 9 \\
\hline & & $\%$ & $30.0 \%$ & $30.0 \%$ & $30.0 \%$ \\
\hline \multirow{2}{*}{\multicolumn{2}{|c|}{ Total }} & $\mathrm{N}$ & 20 & 10 & 30 \\
\hline & & $\%$ & $100.0 \%$ & $100.0 \%$ & $100.0 \%$ \\
\hline \multicolumn{2}{|c|}{ Chi-square } & \multicolumn{4}{|c|}{1.00} \\
\hline \multicolumn{2}{|c|}{ Sig. } & \multicolumn{4}{|c|}{$1.00 \mathrm{NS}$} \\
\hline
\end{tabular}

Table (6): CMV virus patient group for age groups.

\begin{tabular}{|c|c|c|c|c|c|c|c|}
\hline & & PCR & \multirow{2}{*}{ Total } & \multirow{2}{*}{$\begin{array}{r}\text { Chi- } \\
\text { square }\end{array}$} & \multirow{2}{*}{ Sig. } \\
\hline & & & Positive & Negative & & & \\
\hline \multirow{8}{*}{ Age } & \multirow{2}{*}{$21-40$} & $\mathrm{~N}$ & 3 & 4 & 7 & \multirow{10}{*}{2.657} & \multirow{10}{*}{$.448^{\mathrm{NS}}$} \\
\hline & & $\%$ & $15.0 \%$ & $40.0 \%$ & $23.3 \%$ & & \\
\hline & \multirow{2}{*}{$41-60$} & $\mathrm{~N}$ & 11 & 4 & 15 & & \\
\hline & & $\%$ & $55.0 \%$ & $40.0 \%$ & $50.0 \%$ & & \\
\hline & \multirow{2}{*}{$61-80$} & $\mathrm{~N}$ & 5 & 2 & 7 & & \\
\hline & & $\%$ & $25.0 \%$ & $20.0 \%$ & $23.3 \%$ & & \\
\hline & \multirow{2}{*}{$>80$} & $\mathrm{~N}$ & 1 & 0 & 1 & & \\
\hline & & $\%$ & $5.0 \%$ & $0.0 \%$ & $3.3 \%$ & & \\
\hline & \multirow{2}{*}{ Total } & $\mathrm{N}$ & 20 & 10 & 30 & & \\
\hline & & $\%$ & $100.0 \%$ & $100.0 \%$ & $100.0 \%$ & & \\
\hline
\end{tabular}

Table (7): Positive CMV virus diagnostic rate of total study for diagnostic techniques.

\section{Discussion}

\begin{tabular}{|c||c|c||c||}
\hline & RESULT & $\mathrm{N}$ & $\%$ \\
\hline \hline \multirow{2}{*}{ CASSETE $^{\mathrm{a}}$} & Positive & 15 & $21.4 \%$ \\
\cline { 2 - 4 } & Negative & 55 & $78.6 \%$ \\
\hline \hline \multirow{2}{*}{ IGG $^{\mathrm{b}}$} & Positive & 25 & $35.7 \%$ \\
\cline { 2 - 4 } & Negative & 45 & $64.3 \%$ \\
\hline \multirow{2}{*}{$\mathrm{IGM}^{\mathrm{c}}$} & Positive & 5 & $7.1 \%$ \\
\cline { 2 - 4 } & Negative & 65 & $92.9 \%$ \\
\hline \multirow{2}{*}{ PCR $^{\mathrm{d}}$} & Positive & 20 & $66.6 \%$ \\
\cline { 2 - 4 } & Negative & 10 & $33.4 \%$ \\
\hline
\end{tabular}

The current study included [90] samples divided into two groups. The first group is the group of patients with renal failure. It consists of [70] samples, [45] samples of males $(64.3 \%)$ and [25] female samples
(35.7\% The control group consisted of [20] samples, [2] male samples $(10.0 \%)$ and [18] samples of females and $90.0 \%$. The results of the present study showed that the number of males with kidney failure is more than females with a significant difference between 
A Comparative study of some Immunological and Molecular Techniques to Detect Cytomegalovirus in patients with Kidney Failure in Diyala Governort Shahad Shaker Mohmmed

the sexes as well as between the two study groups where $\mathrm{P}$ (value) $<0.001$ as in Table (1), and this result was aggread with the results [10][11]. [12] found that the cause of male injury more than females in renal failure is due to the daily effort of males as compared to females, in addition to the increase in muscle mass in males than females Leading to a high proportion of creatinine in males and kidney damage.

In this study, one of the common immunological techniques, cassette technique, was used. After the examination of the samples of patients with renal failure and control samples, the current results showed that the CMV test results were 15 samples of 70 samples and $21.4 \%$ The mean of the control samples was [4] of the total [20] (20.0\%). There was no statistically significant difference at the $\mathrm{P}$ value $>0.05$ as shown in Table (2) The results were consistent with the results obtained by [13] he found in his study the presence (CMV) serum in patients with kidney failure compared to control. The proportion of positive serological differ for this virus in patients with hemodialysis and that the cause of this variation is linked to the number of patients screened, the geographical distribution and sensitivity of the immunological techniques used to determine the Anti-CMV antibodies [14 ].

Table(3)shows the immunoglobulin antibody (IgM) of the cytomegalovirus virus between the two groups of patients with apparent renal failure. The number of positive $\operatorname{IgM}$ patients was $5(7.1 \%$, ) while the number of positive antibodies was positive [1] (6.67\%). However, no significant differences were observed at the $P$ value $<0.05$. Table(4) shows the $\mathrm{IgG}$ antibody resistance of human cell amplifier virus between The two study groups of patients with renal failure and apparent healthy, as the number of patients positive IgG antibody for this virus (25) $35.7 \%$ of the total [70] samples of patients, while the number of healthy positive IgG antibody for this virus [3] (15\%) of the total [20] with a significant difference of statistical significance at the level of probability $\mathrm{P}$ The results were consistent with the results obtained by the researcher [14] in the study conducted in Tikrit governorate on patients with blood dialysis, where the percentage of patients positive IgG antibody was (87.9\%). In other studies,[15] reported that CMV infection in patients with dialysis was $98 \%$ (IgG) and $\operatorname{IgG} 11 \%$ of the $\operatorname{IgM}$ antibody against CMV. A study was conducted in Antakya, Turkey, to determine the infection of this virus among blood dialysis patients. The IgG antibody ratio was ( $99.6 \% \%$ )[16]. The results of the current study were positive for the human cytomegalovirus virus among the group of patients with renal dysfunction for males and females using one of the sensitive molecular techniques, PCR. The results showed that the number of infected males was positive for the interaction (14 out of 20) (70\%), while the number of females was [6] (30\%) of the total 20 statistically noting that there were no statistically significant differences between the two 
groups at the level $\mathrm{P}$ value $<0.05)$. Came in line with the results obtained by the researcher [17] The number of males diagnosed with PCR was 24, while the number of females was 20. The differences in the results were due to the difference in the size of the sample in addition to the different times for the collection of blood samples from patients and the stage of disease [17]. As shown in Table (5).

Results of the test for the diagnosis of PCR ,the group of patients with renal impairment of both sexes for age groups. The table showed that the age group (21-40) gave positive interaction and by $15 \%$ and the number [3]. The age group (41-60) (55\%) and the number [11] and the age group (61$80)$ gave a positive rate $(25 \%)$ and the number [5] and the last age group (80>) gave a positive rate (5\%) and the number [1] There were significant differences at a probability level of (448) between age groups and both sexes ie $\mathrm{P}>0.05$. The following results show that the age group (41-60) gave the highest rate of infection among the age groups (55\%), as shown in Table (6) that the high percentage of deaths that can be caused by this virus regardless of the variables Age, gender, level of education, health awareness and social conditions are the length of treatment with blood dialysis, as well as damage to the internal kidney layers as a result of injury [18]. When comparing immunological and molecular techniques to diagnose human amplifier virus in patients with renal failure, the rapid technique (Cassette technique) gave serological positive $(21.4 \%$ and $15 \%)$ of the total [70] samples of the two groups, but the ELISA technique gave positive $(25.7 \%)$ and IgM antibody (7.1\%) [5] of the total [70] samples for the two study groups. the(PCR) was positive for diagnosis by (66.6\%) Of the total [30] samples of the two study groups These results show that the current PCR technology is the best diagnostic techniques for the diagnosis of the amplifier virus For cells because they have the highest positive percentage $(66.6 \%)$ among the other techniques used in this study, as shown in Table (7).

\section{References}

[1] William .J Marshall and Stephen Bangent Willy, J.M., Serwood, L.M. and Woolverton, C.J. Prescott, Harley and Klein's Microbiology.(2008)7th ed. McGraw-Hill companies. Inc. United States of America. : 933.

[2] Brooks, G.F., Carroll, K.C., Butel, J.S., Morse, S.A. and Mietzner, T.A. Jawetz, Melnick and Adelberg's Medical Microbiology.(2010) 25th ed. McGraw-Hill companies. Inc.United States of America. ; 467-488.

[3] Trkulic, M., Jovanovic, D., Ostojic, G., Kovacevic, Z. and Taseski, J. Cytomegalovirus infection in patients with kidney diseases. Vojnosanit Pregl,(2000) 57(5), : 63-67.

[4] Cannon, M.J., Schmid, D.S. and Hyde, T.B. Review of cytomegalovirus seroprevalence and demographic characteristics associated with infection. Rev Med Virol,(2010) 20(4), 202-213. [5] 
A Comparative study of some Immunological and Molecular Techniques to Detect Cytomegalovirus in patients with Kidney Failure in Diyala Governort

Wong, S. SH. Cytomegalovirus prophylaxis in renal transplant patients. Medical Bulletin,(2006) 11 (5), :14-15.

[6] Hecker, M., Qiu, D., Marquardt, K., Bein, G. and Hackstein, H.( 2004). Continuous cytomegalovirus seroconversion in a large group of healthy blood donors. Vox Sang. (2004): 41-44.

[7] Adjei, A.A., Armah, H.B. and NarterOlaga, E.G. Seroprevalence of Cytomegalovirus among some voluntary blood donors at the 37 Military Hospital, Accra, Ghana. Ghana Med J,(2006) 40, : 99104.

[8] Ricci; Zaccaria; Ronco; Claudio. New insights in acute kidney failure in the critically ill. Swiss Medical Weekly (2012)142, 13662.

[9] Katzung ; Bertram G.( 2007). Basic and Clinical .Kay, W. R. (2012) . A Study of Natural Killer Cells in Renal Failure and in Patients at Cardiovascular Risk. M.Sc.Thesis ,Coll.Sci, University of Glasgow, UK; , :100 -150 .

[10] Shamkhi , F. B. ; El-Yassin , H. D. and Abd, K.H. (2012). Cystatin C as a Biomarker for Early Detection of Acute Rejection Post Kidney Transplantation. Msc. Thesis, College of Medicine, Baghdad University : 44.

[11] Jumaah, I. A. M.. A study of some biochemical parameters in blood serum of patients with chronic renal failure .Journal of Basrah Researches .(2013) 39 (4) : 22. [12]Wilson, M.. Bacteriology of humans.1st ed. Blackwell publishing. Oxford.(2008) U.K.

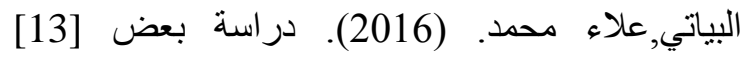

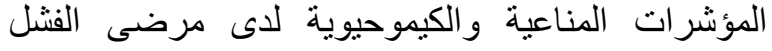
الكلوي في محافظة ديالى.رسالة ماجستير,كلية العلوم لإئية جامعة ديالى

[14] Saadoon, I. H. Frequency of CMVInfection among Hemodialysis Patients in Tikrit City. Iraqi Journal of Science.(2015) 56(3).: 2523-2528.

[15] Abou-El-Yazed, E., El-Hoseny, I., Kasim, K., El-Sadek, A. and Amar, M.. Prevalence of cytomegalovirus infection among patients undergoing hemodialysis. Egypt J Immunol,(2008) 15 (2), : 33- 41.

[16] Ocak, S.; Duran, N. and Esklocak, A.F. Seroprevalence of Cytomegalovirus antibodies in haemodialysis patients. Turk $\mathbf{J}$ Med Sci,(2016) 36 (3),: 155-158. [17] ALKhaweledy,A.J ;AL-Ammar ,M.H.and ALKhozai ,M.Ziad .Cytomegalovirus infection are the most common infection among patients with renal failure at AL-Najaf province. Photon journal of microbiology (2014).(107):200-206.

[18] Michiel G.H.; Betjes, Nicolle H.R.; Litjens, RobertMiller, S. Adult Nurse Practitioner certification Review Guide . 5th ed. Jones and Bartlett Learning, USA .(2013).93. 